\title{
Adaptive Functioning in Students with Cochlear Implants Assessed in Spain through the Strengths and Difficulties Questionnaire
}

\author{
Contrast of opinions between the classroom teaching staff and the speech, language and hearing specialist staff \\ Olga $\mathrm{M}^{\mathrm{a}}$ Alegre de la Rosa ${ }^{1}$, David Pérez-Jorge ${ }^{1}$, \\ $\mathrm{M}^{\mathrm{a}}$ del Carmen Rodríguez-Jiménez ${ }^{1}$ \& Ana Isabel González Herrera ${ }^{1}$ \\ ${ }^{1}$ Professor at Universidad de La Laguna (ULL), Faculty of Education, Department of Didactics and Educational \\ Research, Tenerife, Spain \\ Correspondence: David Pérez-Jorge, Faculty of Education, Department of Didactics and Educational Research, \\ Universidad de La Laguna (ULL), Tenerife, Canary Islands, Spain. E-mail: dpjorge@ull.edu.es
}

Received: November 6, 2017 Accepted: November 24, 2017 Online Published: December 1, 2017

doi:10.5539/gjhs.v10n1p129 URL: https://doi.org/10.5539/gjhs.v10n1p129

This study is framed within the Cochlear Implant Project of the Canary Islands (Spain): a research on educational inclusion, technological resources and services, and quality of family life perceptions, subsidized by the CajaCanarias Foundation under reference number: CSOCSED03 with a duration of three years (1/1/2015 to 12/31/2017).

\begin{abstract}
Cochlear implantation has become increasingly accepted as an option for early implantation in the deaf. The aim of this study was to compare the opinions of 250 classroom teachers and 200 speech, language and hearing specialist teachers regarding the behavior and emotions of the students with cochlear implants using the Strengths and Difficulties Questionnaire (SDQ), which is divided between 5 scales: a) emotional symptoms, b) conduct problems, c) prosocial behavior, d) peer relationship problems, and e) hyperactivity/inattention. The results have shown that there are important discrepancies between the two, both in the externalization of conduct problems and in prosocial behaviors, although there are notable coincidences related to attention factors and to the exceptional presence of emotional symptoms of these students in new situations.
\end{abstract}

Keywords: cochlear implant, emotions, prosocial behavior, social relationships

\section{Introduction}

Studies on children's mental health show that between $10 \%$ and $20 \%$ of Spanish children suffer from some type of mental disorder (Fonseca, Lemos, \& Muñíz, 2011). A powerful and widely used screening tool for children's mental health is the Strengths and Difficulties Questionnaire (SDQ) (Goodman, 1997), which has demonstrated its psychometric properties and discriminative validity in different cultural contexts. In Spain, the SDQ has been validated on several occasions with a clinical population (Rodríguez, 2006a) as well as with a general population in the Canary Islands (Rodríguez, 2006b).

Behavioral and emotional problems affect, therefore, an important part of the child and adolescent population which must be considered, furthermore, within the socio-cultural context of each individual (Mata, Suárez, Torres, Carro, \& Ortega, 2009).

Different studies reveal improvements in the functional and communication skills of the implanted (Rodríguez, Pérez-Jorge, Alegre, Leal, \& Suárez, 2016; Bat-Chava, Martin, \& Kosciw, 2005; Blamey, Barrey, Bow, Sarant, \& Paatsch, 2001; Connor, Hieber, Arts, \& Zwolan, 2000; Geers, Nicholas, \& Sedey, 2003; Svirsky et al., 2000). A psycholinguistic profile of implanted children was designed within the study of Alegre, Rodríguez, Villar, Pérez-Jorge and Marrero (2014) which evidenced the positive effect of early implantation in language development in deaf children.

However, the success of the results following cochlear implantation is neither immediate nor assured (Geers, 2003). It is important to emphasize the significant variability of the results following implantation (Bat-Chava et al., 2005; Purdy, Chard, Moran, \& Hodgson, 1995; Sach \& Whynes, 2005; Spencer, 2004; Spencer \& Marschark, 2003). In 
fact, continuous efforts in rehabilitation are imperative following cochlear implantation to make sure that the procedure is effective (Christansen \& Leigh, 2002).

Understanding that language is the main path for integrating information (Delgado, 2011; Jiménez, 2011) and, in turn, many of the norms and conducts of socialization, the communication difficulties present in children with hearing loss may be a barrier for acquiring the prosocial conducts and skills that enable integration in their contexts of reference, which are fundamentally hearing-based (Calderón \& Greenberg, 2003; Schorr, 2005).

As stated by Bat-Chava and Deignan (2001), the parents of implanted children admit that following implantation there is an important improvement in their child's integration in his/her context of reference. However, in spite of these improvements, they also express that there are still some communication problems, particularly regarding those related to social interaction.

In this sense, the two reference contexts of the child (family and school) seem to agree that relation difficulties are due, in most cases, to a delay in the development of specific social and communication skills, such as comprehension problems or regarding the subtlety of nuances in social interactions. These difficulties create limitations in the child when establishing friendships with peers, as well as problems regarding his/her independence to participate in school and social life (Punch \& Hyde, 2010).

Some studies, such as Quittner, Smith, Osberger, Mitchell and Katz (1994), Smith, Quittner, Osberger and Miyamoto (1998) and Yucel and Derim (2008), suggest that children with hearing loss find it difficult to remain attentive and are easily distracted and impulsive when requested to complete different tasks. These results are similar to those gathered by Horn, Davis, Pisoni and Miyamoto (2005) who carried out a study that aimed to analyze the development of attention skills in children with cochlear implants. They demonstrated that even though after the implantation process the children continued to present very poor results in the tasks aimed at evaluating their ability to sustain their attention, these results improved slightly after several years using the cochlear implant.

The ability of implanted children to communicate within their contexts of reference greatly affects the development of prosocial behaviors that would allow the child to form close social relationships with others (Stinson \& Whitmire, 2000). Children with cochlear implants may experience difficulties in acquiring this type of behavior, particularly if it has been a late implantation, since this leads to a delay in the development of the necessary communication skills (Delgado, 2011; Jiménez, 2011; Rodríguez, 2013). As a consequence, many of the relationship difficulties experienced by implanted children within the school environment are due to their limited production of intelligible speeches as well as a limited understanding of the spoken messages they hear (Martín, Bat-Chava, Lalwani, \& Waltzman, 2010; Remmel \& Peters, 2009; Schorr, Roth, \& Fox, 2009).

The fear of mockery and laughter from their peers, their inability to participate accordingly in the conversations or debates that are generated in the classroom, or even, being underestimated by their peers (Punch \& Hyde, 2010), tends to create in these children greater emotional imbalances (fear, anxiety, frustration), than in their hearing peers even though such levels usually decline after implantation, as pointed out by Ferginger, Holzinger, and Pollard (2012), Huber and Kipman (2011) and Theunissen, et al., (2012). As a consequence of this, and although it may seem that implantation favors a better integration within the school context, many students with cochlear implants reject interactions with their peers, even though they have their initial acceptance. This may be due to their inability to interact verbally at the same pace as their peers, which consequently limits opportunities to develop similar prosocial skills and behaviors (Dye \& Hauser, 2014; Punch \& Hyde, 2010).

Schorr (2005) stated that boys and girls between the ages of 5 and 9 experienced the same level of solitude as hearing children of the same age. In the case of children implanted between the ages of 9 and 14, low self-perception and exhibitions of solitude were greater to those of their hearing peers. These data highlight the importance of the benefits of early implantation in children (Francis, Koch, Wyatt, Niparko, 1999, Holman et al., 2013, Jimenez, 2011, Rodriguez, 2013).

On the other hand, the possible consequences derived from communication difficulties of children with cochlear implants and the possible effects on their development (Calderón \& Greenberg, 2003; Quittner, Leibach, \& Marciel, 2004; Stevenson, Kreppner, Pimperton et al., 2009), has led these authors to suggest that there are more behavioral problems in implanted students than in their hearing classmates (Anmyr, Larsson, Olsson, and Freijd, 2012; Worsfold \& Kennedy, 2015; Vostanis, Hayes, Du Feu, \& Warren, 1997).

This study aims to research the behavior and emotional aspects of the students with early implantations, as perceived by the classroom teachers and the speech, hearing and language specialist teachers using the SDQ. This questionnaire is a brief screening tool that assesses psychological problems in children and adolescents regarding 
behavior, emotions and interpersonal interactions (Goodman, 1997), and which has been translated into more than 60 languages. Since its construction, a large number of researches have studied its psychometric properties gathering evidence on its reliability and validity (Rivera, 2013).

\section{Method}

\subsection{Participants}

The sample of this study consisted of 250 classroom teachers and 200 speech, language and hearing specialists (SLH) of children with early cochlear implants, aged between 4 and 16 and enrolled in schools of the Autonomous Community of the Canary Islands. The teachers were chosen because they taught the children involved. The identification data of the teacher sample can be seen in Table 1 .

Table 1. The identification data of the teacher

\begin{tabular}{lll}
\hline & Classroom Teachers & SLH Specialists \\
\hline Gender & Men: $28 \%$ & Men: $19 \%$ \\
& Women: $72 \%$ & Women: $81 \%$ \\
Age & Mean: 50.3 years & Mean: 46.5 years \\
Years of Experience & Sd: 3.2 & Sd: 2.3 \\
& Mean: 10.2 years & Mean: 9.3 years \\
\hline
\end{tabular}

The mean chronological age of the implanted children on which teachers gave their opinion was 132.57 months $(\mathrm{Sd}=52.37)$ and in terms of educational level, 23\% attended Pre-school, 43\% Elementary School , 26\% Middle School and 6\% High School.

\subsection{Materials}

As mentioned above, in order to gather data on the opinion of staff regarding prosocial conduct and behavior of implanted students, we used the "Strengths and Difficulties Questionnaire (SDQ)" by Goodman (1997) in his version for teachers in the subscale applicable to the age range between 4 and 16. This test helps detect disruptive emotional conduct that can compromise the behavior of children from 3 to 16 years old. In short, it is used to analyze the emotional and behavioral adjustment of boys and girls, in our case, with cochlear implants.

The questionnaire consists of 25 items divided between 5 scales: a) emotional symptoms, b) conduct problems, c) prosocial behavior, d) peer relationship problems e) hyperactivity/inattention. Each subscale is assigned 5 items that are scored from 0 to 2, on a scale that is set as follows: False ( 0 points), Somewhat True (1 point) and Certainly True ( 2 points). For the case of items 7, 11, 14, 21 and 25 a reverse scoring scale is used.

\subsection{Procedure}

As a first step to gathering the data necessary for the study, an initial contact was made by phone with the different directors of the schools in which the implanted students were enrolled. Having received the pertinent authorizations, an informative letter was sent to the parents of the children with cochlear implant requesting authorization to allow both classroom and speech, language and hearing specialist teachers to respond to the questionnaire in relation to information regarding their child. Once these were obtained, the questionnaires were handed out to the different professionals in the schools.

\subsection{Data Analysis}

The SPSS statistical package (see 21) was used to analyze the frequency distribution of the teachers' evaluations on different aspects related to the conduct and attitudes of the implanted minors (descriptive analysis of the SDQ scale).

The Kappa index (Cohen, 1960) was calculated for each of the items in order to assess the degree to which teachers and SLH specialists agreed, as well as to determine the percentage of the agreement. In this way, it was determined, at a statistical level, whether teachers expressed agreement or not when assessing the conduct and attitude of students.

\section{Results}

To start with, we analyzed the discrepancy of opinions among staff on a descriptive level. In this way, and observing the percentage of answers of the teachers in the false category, differences were noticed regarding the 
first 12 items (Table 2); it was observed that teachers hardly differed in their answers in the false category in relation to items $1,2,3,5,8,10$ and 12 . However, items 4 and 9 showed a $10 \%$ difference in answers within this category, so that the differences in opinion of the teaching staff were greater. Finally, in item 6 there was a 16\% difference in opinion turning it into the item manifesting the most differences in opinion.

However, for items 7 and 11 the most significant differences were detected at the somewhat true and certainly true levels respectively, so that in these two cases there was a change in trend with respect to the rest of the items.

Table 2. Speech, language and hearing Specialists' and Classroom teachers' answers to the items

\begin{tabular}{|c|c|c|c|c|}
\hline & & SL H & $\begin{array}{l}\text { Classroom } \\
\text { Teachers }\end{array}$ & $\begin{array}{l}\text { Difference in } \\
\text { criteria }\end{array}$ \\
\hline \multirow{3}{*}{1 Considerate of other people's feelings } & False & $0.0 \%$ & $3.3 \%$ & $3.3 \%$ \\
\hline & Somewhat True & $43.3 \%$ & $33.3 \%$ & $10.0 \%$ \\
\hline & Certainly True & $56.7 \%$ & $63.3 \%$ & $6.7 \%$ \\
\hline \multirow{3}{*}{2 Restless, overactive, cannot stay still for long } & False & $56.7 \%$ & $53.3 \%$ & $3.3 \%$ \\
\hline & Somewhat True & $30.0 \%$ & $30.0 \%$ & $0.0 \%$ \\
\hline & Certainly True & $13.3 \%$ & $16.7 \%$ & $3.3 \%$ \\
\hline \multirow{3}{*}{$\begin{array}{l}3 \text { Often complains of headaches, stomach-aches or } \\
\text { sickness }\end{array}$} & False & $70.0 \%$ & $66.7 \%$ & $3.3 \%$ \\
\hline & Somewhat True & $26.7 \%$ & $20.0 \%$ & $6.7 \%$ \\
\hline & Certainly True & $3.3 \%$ & $13.3 \%$ & $10.0 \%$ \\
\hline \multirow{3}{*}{$\begin{array}{l}4 \text { Shares readily with other children (treats, toys, } \\
\text { pencils etc.) }\end{array}$} & False & $0,0 \%$ & $10.0 \%$ & $10.0 \%$ \\
\hline & Somewhat True & $56.7 \%$ & $50.0 \%$ & $6.7 \%$ \\
\hline & Certainly True & $43.3 \%$ & $40.0 \%$ & $3.3 \%$ \\
\hline \multirow{3}{*}{5 Often has temper tantrums or hot tempers } & False & $70.0 \%$ & $70.0 \%$ & $0.0 \%$ \\
\hline & Somewhat rue & $23.3 \%$ & $30.0 \%$ & $6.7 \%$ \\
\hline & Totally True & $6.7 \%$ & $0.0 \%$ & $6.7 \%$ \\
\hline \multirow{3}{*}{6 Rather solitary, tends to play alone } & False & $80.0 \%$ & $63.3 \%$ & $16.7 \%$ \\
\hline & Somewhat True & $13.3 \%$ & $23.3 \%$ & $10.0 \%$ \\
\hline & Cerrtainly True & $6.7 \%$ & $13.3 \%$ & $6.7 \%$ \\
\hline \multirow{3}{*}{$\begin{array}{l}7 \text { Generally obedient, usually does what adults } \\
\text { request }\end{array}$} & False & $56.7 \%$ & $66,7 \%$ & $10.0 \%$ \\
\hline & Somewhat True & $40.0 \%$ & $23.3 \%$ & $16.7 \%$ \\
\hline & Certainly True & $3.3 \%$ & $10.0 \%$ & $6.7 \%$ \\
\hline \multirow{3}{*}{8 Many worries, often seems worried } & False & $73.3 \%$ & $73,3 \%$ & $0.0 \%$ \\
\hline & Somewhat True & $23.3 \%$ & $20.0 \%$ & $3.3 \%$ \\
\hline & Certainly True & $3.3 \%$ & $6.7 \%$ & $3.3 \%$ \\
\hline \multirow{3}{*}{9 Helpful if someone is hurt, upset or feeling ill } & False & $0.0 \%$ & $10.0 \%$ & $10.0 \%$ \\
\hline & Somewhat True & $56.7 \%$ & $46.7 \%$ & $10.0 \%$ \\
\hline & Certainly True & $43.3 \%$ & $43.3 \%$ & $0.0 \%$ \\
\hline \multirow{3}{*}{10 Constantly fidgeting or squirming } & False & $83.3 \%$ & $80.0 \%$ & $3.3 \%$ \\
\hline & Somewhat True & $6.7 \%$ & $6.7 \%$ & $0.0 \%$ \\
\hline & Certainly True & $10.0 \%$ & $13.3 \%$ & $3.3 \%$ \\
\hline \multirow{3}{*}{11 Has at least one good friend } & False & $83.3 \%$ & $66.7 \%$ & $16.7 \%$ \\
\hline & Somewhat True & $13.3 \%$ & $23.3 \%$ & $10.0 \%$ \\
\hline & Certainly True & $3.3 \%$ & $10.0 \%$ & $6.7 \%$ \\
\hline \multirow{3}{*}{12 Often fights with other children or bullies them } & False & $70.0 \%$ & $70.0 \%$ & $0.0 \%$ \\
\hline & Somewhat True & $23.3 \%$ & $20.0 \%$ & $3.3 \%$ \\
\hline & Certainly True & $6.7 \%$ & $10.0 \%$ & $3.3 \%$ \\
\hline
\end{tabular}

In terms of items 13 to 25 (Table 3), we observed some relevant issues regarding the false and certainly true categories as well. The items in which the opinions among staff hardly differed in relation to the false category were: $13,14,18,20,24$, in which the differences between both groups of teachers descended to between $3 \%$ and $6 \%$. However, in items 15, 19, 22 (classroom teacher responses follow a constant distribution) the differences in response between the groups of teachers in the false category ranged from $10 \%$ to $23 \%$. A slightly higher percentage of differences was seen in item 23 , where the speech, language and hearing specialists gave a $23 \%$ higher response in the false category than the classroom teachers. On the other hand, regarding the certainly true category, the items in which the most differences were observed were 15,16,17, 20 and 25, where there was a 
difference of between $10 \%$ and $20 \%$ between classroom teachers and the SLH specialists.

Table 3. Speech, language and hearing Specialists' and Classroom Teachers' (continued)

\begin{tabular}{|c|c|c|c|c|}
\hline & & SLH Teacher & Class Teacher & Difference in criteria \\
\hline \multirow{3}{*}{13 Often unhappy, down-hearted or tearful } & False & $80.0 \%$ & $76.7 \%$ & $3.3 \%$ \\
\hline & Somewhat True & $16.7 \%$ & $16.7 \%$ & $0.0 \%$ \\
\hline & Certainly True & $3.3 \%$ & $6.7 \%$ & $3.3 \%$ \\
\hline \multirow{3}{*}{14 Generally liked by other children } & False & $46.7 \%$ & $56.7 \%$ & $10.0 \%$ \\
\hline & Somewhat True & $43.3 \%$ & $40.0 \%$ & $3.3 \%$ \\
\hline & Certainly True & $10.0 \%$ & $3.3 \%$ & $6.7 \%$ \\
\hline \multirow{3}{*}{15 Easily distracted, concentration wanders } & False & $43.3 \%$ & $26.7 \%$ & $16.7 \%$ \\
\hline & Somewhat True & $400 \%$ & $66.7 \%$ & $26.7 \%$ \\
\hline & Certainly True & $16.7 \%$ & $6.7 \%$ & $10.0 \%$ \\
\hline \multirow{3}{*}{$\begin{array}{l}16 \text { Nervous or clingy in new situations, } \\
\text { easily loses confidence }\end{array}$} & False & $63.3 \%$ & $53.3 \%$ & $10.0 \%$ \\
\hline & Somewhat True & $30.0 \%$ & $20.0 \%$ & $10.0 \%$ \\
\hline & Certainly True & $6.7 \%$ & $26.7 \%$ & $20.0 \%$ \\
\hline \multirow{3}{*}{17 Kind to younger children younger } & False & $6.7 \%$ & $10.0 \%$ & $3.3 \%$ \\
\hline & Somewhat True & $33.3 \%$ & $50.0 \%$ & $16.7 \%$ \\
\hline & Certainly True & $60.0 \%$ & $40.0 \%$ & $20.0 \%$ \\
\hline \multirow{3}{*}{18 Often lies or cheats } & False & $66.7 \%$ & $63.3 \%$ & $3.3 \%$ \\
\hline & Somewhat True & $23.3 \%$ & $30.0 \%$ & $6.7 \%$ \\
\hline & Certainly True & $10,0 \%$ & $6.7 \%$ & $3.3 \%$ \\
\hline \multirow{3}{*}{19 Picked on or bullied by other children } & False & $86.7 \%$ & $66.7 \%$ & $20.0 \%$ \\
\hline & Somewhat True & $6.7 \%$ & $23.3 \%$ & $16.7 \%$ \\
\hline & Certainly True & $6.7 \%$ & $10.0 \%$ & $3.3 \%$ \\
\hline \multirow{3}{*}{$\begin{array}{l}20 \text { Often volunteers to help others (parents. } \\
\text { teachers. other children) }\end{array}$} & False & $26.7 \%$ & $23.3 \%$ & $3.3 \%$ \\
\hline & Somewhat True & $40.0 \%$ & $53.3 \%$ & $13.3 \%$ \\
\hline & Certainly True & $33.3 \%$ & $23.3 \%$ & $10.0 \%$ \\
\hline \multirow{3}{*}{21 Think things out before acting } & False & $13.3 \%$ & $10.0 \%$ & $3.3 \%$ \\
\hline & Somewhat True & $63.3 \%$ & $56.7 \%$ & $6.7 \%$ \\
\hline & Certainly True & $23.3 \%$ & $33.3 \%$ & $10.0 \%$ \\
\hline \multirow{3}{*}{22 Steals from home. school or elsewhere } & False & $86.7 \%$ & $100.0 \%$ & $13.3 \%$ \\
\hline & Somewhat True & $13.3 \%$ & $0.0 \%$ & $13.3 \%$ \\
\hline & Certainly True & $0.0 \%$ & $0.0 \%$ & $0.0 \%$ \\
\hline \multirow{3}{*}{$\begin{array}{l}23 \text { Gets on better with adults than with other } \\
\text { children }\end{array}$} & False & $86.7 \%$ & $63.3 \%$ & $23.3 \%$ \\
\hline & Somewhat True & $6.7 \%$ & $30.0 \%$ & $23.3 \%$ \\
\hline & Certainly True & $6.7 \%$ & $6.7 \%$ & $0.0 \%$ \\
\hline \multirow{3}{*}{24 Many fears. easily scared } & False & $53.3 \%$ & $46.7 \%$ & $6.7 \%$ \\
\hline & Somewhat True & $33.3 \%$ & $33.3 \%$ & $0.0 \%$ \\
\hline & Certainly True & $13.3 \%$ & $20.0 \%$ & $6.7 \%$ \\
\hline \multirow{3}{*}{$\begin{array}{l}25 \text { Sees tasks through to the end. good } \\
\text { attention span }\end{array}$} & False & $43.3 \%$ & $30.0 \%$ & $13.3 \%$ \\
\hline & Somewhat True & $40.0 \%$ & $50.0 \%$ & $10.0 \%$ \\
\hline & Certainly True & $16.7 \%$ & $20.0 \%$ & $3.3 \%$ \\
\hline
\end{tabular}

Given that the analysis of discrepancies at the descriptive level was not enough to evaluate the degree of agreement of both groups of teachers regarding the behaviors and attitudes of students with cochlear implants, we proceeded to calculate the Kappa index for each of the items (Tables 3 and 4). In this way, it was possible to assess the degree of agreement as significant, in addition to offering the percentage of agreement between the speech, language and hearing specialists and the classroom teachers when classifying the behavior of the implanted children. In order to assess the intensity of the agreement, we will use the Viera and Garrett scale $(2005$, p. 362), which classifies the degree of agreement as follows: " $<0.01$ Less than chance agreement; 0.01-0.20 Slight agreement; 0.21-0.40 Fair agreement; 0.41-0.60 Moderate agreement; 0.61-0.80 Substantial agreement; 0.81-0.99 Almost perfect agreement".

Table 4 shows the items in which the degree of agreement was significant $(p<0.05)$. The two items with the highest percentage of agreement were 1 and 24, reaching $46 \%$ and $45 \%$ respectively, allowing us to consider it a Moderate agreement. A somewhat lower degree of agreement (between $37 \%$ and $41 \%$ ) was observed in items $12,14,18,15$, 
5, 2 and 16. In all of these items the agreement could be defined as a fair agreement. Finally, in items 3,20 and 6 the degree of agreement, despite being significant, was lower than the previous ones and of a lower intensity than the rest of the items.

Table 4. Items in which the Speech, language and hearing Specialists and the Classroom Teachers show a significant degree of agreement *

\begin{tabular}{ll}
\hline Items & \% of agreement (Kappa coefficient) \\
\hline 1 Considerate of other people's feelings & 46.3 \\
24 Many fears, easily scared & 45.7 \\
12 Often fights with other children or bullies them & 41.6 \\
14 Generally liked by other children & 40.4 \\
18 Often lies or cheats & 40.1 \\
15 Easily distracted, concentration wanders & 39.6 \\
5 Often has temper tantrums or hot tempers & 39.4 \\
2 Restless, overactive, cannot stay still for long & 37.4 \\
16 Nervous or clingy in new situations, easily loses confidence & 37.3 \\
3 Often complains of headaches, stomach-aches or sickness & 29.9 \\
20 Often volunteers to help others (parents, teachers, other children) & 27.8 \\
6 Rather solitary, tends to play alone & 26.5 \\
\hline
\end{tabular}

*: Sigma $<0.05$.

Table 5, for its part, displays the items with a degree of agreement that was not statistically significant. Thus, although items $8,9,10$ and 7 had a fair agreement, this agreement was not relevant in statistical terms. It is possible to observe the existence of items $(4,11,19,25$ and 13$)$ in which the teacher showed between $20 \%$ and $15 \%$ slight agreement. Finally, items 23, 17 and 21 obtained a degree of agreement of less than $6 \%$. The items shown in Table 5 have insignificant degrees of agreement, thus it can be affirmed that there is discrepancy in these items.

Table 5. Items in which the Speech, language and hearing Specialists and the Classroom Teachers DO NOT show a significant degree of agreement *

\begin{tabular}{ll}
\hline Items & \% of agreement (Kappa coefficient) \\
\hline 22 Steals from home, school, or elsewhere & $---* *$ \\
8 Many worries, often seems worried & 27.4 \\
9 Helpful if someone is hurt, upset or feeling ill & 27.0 \\
10 Constantly fidgeting or squirming & 26.1 \\
7 Generally obedient, usually does what adults request & 23.9 \\
4 Shares readily with other children (treats, toys, pencils etc.) & 20.2 \\
11 Has at least one good friend & 18.7 \\
19 Picked on or bullied by other children & 16.7 \\
25 Sees tasks through to the end, good attention span & 16.2 \\
13 Often unhappy, down-hearted or tearful & 15.9 \\
23 Gets on better with adults than with other children & 6.2 \\
17 Kind to younger children younger & 3.4 \\
21 Thinks things out before acting & 3.0 \\
\hline
\end{tabular}

*: Sig $>0.05$.

**: Not calculated as it is a constant. 


\section{Discussion and Conclusions}

The main objective of this study was to get to know and compare the opinion of the classroom teachers and the speech, language and hearing specialist teachers in terms of the relationships and integration of implanted students within the school environment. To this end, five categories were considered that fall into the afore-mentioned characteristics, namely: possible inattention and behavioral problems; the presence or absence of difficulties in relating to their peers; prosocial conducts and emotional characteristics.

Considering that no item has obtained a degree of agreement above $46 \%$ in regards to the evaluation of conduct and attitudes of students with cochlear implants, we can state that there are several discrepancies between the speech, language and hearing specialist teachers and the classroom teachers.

In relation to the attention problems of students with cochlear implants, the results found in this study have shown that, although for most classroom teachers and speech, language and hearing specialist teachers the lack of attention, distractions and impulsivity do not suppose daily and generalizable behaviors for all the students implanted since for a high percentage of these, these type of behaviors are present exceptionally. This result, following the direction of Silvestre (2003) and Lesser and Easser (1972), may be motivated by the combination between the frustration generated by their difficulties to communicate and their tendency to be impulsive.

Furthermore, along the lines of Dye and Hauser (2014), Horn, Davis et al. (2005) and Yucel and Derim (2008) it is important to note the high percentage of classroom teachers and speech, language and hearing specialist teachers who expressed that the implanted students displayed difficulties to stay attentive throughout the completion of tasks. Some studies (Quittner et al., 2007, Quittner et al. 1994; Smith, Quittner et al.1998) suggest that even though in the months following implantation there are substantial improvements in the tasks that require greater and sustained visual attention, it is not until the children have reached 8 or 9 years of age that they are able to make better use of the cochlear implant due to the strong relationship that exists between the level of performance required in each task and the age of the children.

Regarding the externalization of behavioral problems, there are many discrepancies that have been observed when assessing the presence of these in children with cochlear implants. For authors like Calderón and Greenberg, (2003), Quittner et al. (2004) or Schorr, (2005) the deprivation of auditory information and communication at an early age may be an obstacle for learning the main behavioral skills. In this sense, SLH specialist and classroom-teacher assessments did not reflect a clear existence of behavioral problems in implanted children. Similar results were obtained in other studies (Anmyr et al. 2012; de Giacomo et al., 2013) in which it was suggested that the implanted children had similar adaptive behaviors to those of their hearing peers.

As for the results obtained from the assessments made by classroom and SLH teachers on prosocial behavior, it was observed that, although most of the students displayed these types of behaviors, it becomes important to note that a high percentage of classroom teachers described the incidence of these behaviors as Somewhat True. Similar to the results obtained in this study, Punch and Hyde (2010) observed that the vast majority of teachers who gave their opinion on the adaptive skills of these children, considered themselves to be in agreement with the idea that the implanted students had developed the social skills in accordance to their age. The studies by De Giacomo et al., (2013) and Martin, et al. (2010) stated that there were no significant differences in the development of prosocial conducts between the implanted students and their hearing peers. Furthermore, in the first of the studies cited, it was possible to relate the use of the cochlear implant to an improvement in the development of prosocial behavior.

According to the results obtained in this study, the presence of emotional symptoms does not imply generalized behaviors in implanted students. However, most of the SLH and classroom teachers have noted the exceptional appearance of emotional symptoms of these students when faced with new situations. This fact is possibly related to their communication limits caused by a hearing deficit in the implanted students and a fear of failure to communicate in new contexts of interaction to which they are not accustomed (Remmel \& Peters, 2009; Schorr et al. 2009). Some studies (Huber \& Kipman, 2011; Stinson \& Whitmire, 2000; Theunissen, et al., 2012) have shown that early implantation is beneficial both for functional and communication skills (Alegre et al. 2014) and helps to prevent and reduce anxiety levels among students with hearing loss. This fact emphasizes the importance of early implantation as a mechanism to reduce the effects of language deprivation in children, in relation to the presence of emotional symptoms and behavioral problems (Bat-Chava \& Deignan, 2001; Francis, Koch, Wyatt, \& Niparko, 1999; Fellinger, Holzinger, \& Pollard, 2012; Holman et al., 2013; Jiménez, 2011; Rodríguez, 2013).

Regarding the presence of related problems in students with cochlear implants and hearing students, the results obtained did not reflect the existence of significant problems. Thus, in matters related to group play, results similar to those obtained by Punch and Hyde (2010) were observed, where at least $64 \%$ of classroom teachers agreed that 
implanted students participated regularly with their teammates in group play. These results fell significantly when the classroom teachers assessed (rating as Certainly True) the acceptance of implanted students in the classroom reaching $46.7 \%$ for classroom teachers and $56.7 \%$ for SLH teachers.

Thus, we can conclude, within the category of attention problems, that although it is not possible to generalize the lack of attention, distractions and impulsivity as daily behaviors, this type of behavior does manifest itself occasionally. A similar trend was reflected by classroom and SLH teachers when assessing the prosocial behaviors of implanted students, where this type of behavior was marked as an exception rather than the norm. Taking into account the results regarding the externalization of behavioral problems and difficulties in relating to their peers we can conclude, in both categories, that there are no significant problems generalizable to all students.

Finally, regarding the category that evaluates the presence of emotional symptoms, the results obtained do not reflect signs of these, although for at least $46.7 \%$ of classroom teachers and $36.7 \%$ of SLH teachers, these students often lose confidence in themselves when faced with emotional situations that are new to them.

The results obtained are the starting point for future studies that address these and other categories, which can lead us to a better understanding of the possible difficulties present in the social and emotional development of children with cochlear implant and their integration in the different family, peer and school contexts.

Furthermore, they allow us to claim with due caution, the different perceptions of the classroom teacher who is a specialist detecting the behavioural and emotional difficulties of children with early on cochlear implants, even if the limitations of the sample do not allow us to generalize this sample in other contexts. The possible implications of this study could be directed to improving assessment tools, as well as to detect the emotional and behavioural difficulties, due to the relevance of these aspects in the psycho-evolutionary development of children with cochlear implants.

\section{Competing Interests Statement}

The authors declare that there are no competing or potential conflicts of interest.

\section{References}

Alegre, O. M., Rodríguez, M. C., Villar, L. M., Pérez-Jorge, D., \& Marrero, S. (2014). Effectiveness of cochlear implants on language development in early implanted children. Sylwan, 160(10), 223-233.

Anmyr, L., Larsson, K., Olsson, M., \& Freijd, A. (2012). Strengths and difficulties in children with cochlear implants-comparing self-reports with reports from parents and teachers. International Journal of Pediatric Otorhinolaryngology, 76(8), 1107-1112. http://dx.doi.org/10.1016/j.ijporl.2012.04.009

Barker, D. H., Quittner, A. L., Fink, N. E., Eisenberg, L. S., Tobey, E. A., \& Niparko, J. K. (2009). Predicting behavior problems in deaf and hearing children: the influences of language, attention, and parent-child $\begin{array}{llll}\text { communication. Development and } & \text { 21(02), 373-392. }\end{array}$ http://dx.doi.org/10.1017/S0954579409000212

Bat-Chava, Y., Martin, D., \& Kosciw, J. (2005). Longitudinal improvements incommunication and socialization of deaf children with cochlear implants and hearing aids: Evidence from parental reports. Journal of Child Psychology and Psychiatry, 46(12), 1287-1296.

Bat-Chava, Y., \& Deignan, E. (2001). Peer relationships of children with cochlear implants. Journal of Deaf Studies and Deaf Education, 6, 186-199. http://dx.doi.org/10.1093/deafed/6.3.186

Blamey, P. J., Barry, J. G., \& Jacq, P. (2001). Phonetic inventory development in young cochlear implant users 6 years postoperation. Journal of Speech, Language \& Hearing Research, 44, 73-79.

Calderon, R., \& Greenberg, M. (2003). Social and emotional development of deaf children. In M. Marschark \& P. E. Spencer (Eds.), Oxford handbook of deaf studies, language, and Education (170-189). New York: Oxford University Press.

Christiansen, J. B., \& Leigh, I. W. (202). Cochlear implants in children: Ethics and choices. Washington DC: Gallaudet University Press.

Cohen. J. (1960). A coefficient of agreement for nominal scales. Educational and Psychological Measurement, 20(1), 37-46. http://dx.doi.org/10.1177/001316446002000104

Connor, C. M., Hieber, S., Arts, H. A., \& Zwolan, T. A. (2000). Speech, vocabulary, and the education of children using cochlear implants: oral or total communication?. Journal of Speech Language \& Hearing Research, 5(43), 1185-1204. 
Delgado. J. J. (2011). Detección precoz de la hipoacusia infantil. Revista Pediátrica de Atención Primaria, 13, 279-97.

De Giacomo, A., Craig, F., D’Elia, A., Giagnotti, F., Matera, E., \& Quaranta, N. (2013). Children with cochlear implants: cognitive skills, adaptive behaviors, social and emotional skills. International journal of pediatric otorhinolaryngology, 77(12), 1975-1979. http://dx.doi.org/10.1016/j.ijporl.2013.09.015

Dye, M. W., \& Hauser, P. C. (2014). Sustained attention, selective attention and cognitive control in deaf and hearing children. Hearing Research, 309, 94-102. https://dx.doi.org/10.1016/j.heares.2013.12.001

Fellinger, J., Holzinger, D., \& Pollard, R. (2012). Mental health of deaf people. The Lancet, 379(9820), 1037-1044. https://dx.doi.org/10.1016/S0140-6736(11)61143-4

Fonseca, E., Paino, M., Lemos, S. Y., \& Muñiz, J. (2011). Prevalencia de la sintomatología emocional y comportamental en adolescentes españoles a través del Strengths and difficulties questionnaire (SDQ). Revista de Psicopatología y Psicología Clínica, 16, 15-25.

Francis, H. W., Koch, M. E., Wyatt, J. R., \& Niparko, J. K. (1999). Trends in educational placement and cost-benefit considerations in children with cochlear implants. Archives Otolaryngology Head Neck Surgery, 125(5), 499-505. https://dx.doi.org/10.1001/archotol.125.5.499

Geers, A. (2003). Predictors of reading skill development in children with early cochlear implantation. Ear \& Hearing, 24, 59-68.

Geers, A., Nicholas, J., \& Sedey, A. (2003). Language skills of children with early cochlear implantation. Ear \& Hearing, 24(1), 2-14.

Goodman, R. (1997). The Strengths and Difficulties Ques-tionnaire: a research note. Journal of Child Psychology and Psychiatry, 38, 581-58. https://dx.doi.org/10.1111/j.1469-7610.1997.tb01545.x

Holman, M. A., Carlson, M. L., Driscoll, C. L., Grim, K. J., Petersson, R.S., Sladen, D. P., \& Flick, R. P. (2013). Cochlear implantation in children 12 months of age and younger, Journal Otology Neurotology, 34(2), 251-258. https://dx.doi.org/10.1097/MAO.0b013e31827d0922

Horn, D. L., Davis, R. A., Pisoni, D. B. \& Miyamoto, R. T. (2005). Development of visual attention skills in prelingually deaf children who use cochlear implants. Ear and hearing, 26(4), 389-408. https://dx.doi.org/10.1097/00003446-200508000-00003

Huber, M., \& Kipman, U. (2011). The mental health of deaf adolescents with cochlear implants compared to their hearing peers. International Journal of Audiology, 50(3), 146-154. http://dx.doi.org/10.3109/14992027.2010.533704

Jiménez, M. S. (2011). El implante coclear en la población infantil. Córdoba, España: Servicio de Publicaciones de la Universidad de Córdoba Recuperado de: http://helvia.uco.es/xmlui/bitstream/handle/10396/5146/9788469447680.pdf?sequence=

Lesser, S. R., \& Easser, B. R. (1972). Personality differences in the perceptually handicapped. Journal of the American Academy of Child Psychiatry, 11(3), 458-466. http://dx.doi.org/10.1016/S0002-7138(09)61203-6

Martín, D., Bat-Chava, Y., Lalwani, A., \& Waltzman, S. B. (2010) Peer relationship of deaf with cochlear implants: Predictors of peer entry and peer interaction success. Journal of Deaf Study and Deaf Education, 16(1), 180-120. http://dx.doi.org/10.1093/deafed/6.3.186

Mata, D., Suárez, A., Torres, C., Carro, A. Y., \& Ortega, E. (2009). Uso del Cuestionario de Capacidades y Dificultades (SDQ) como instrumento de cribado de trastornos psiquiátricos en la consulta de pediatría de Atención Primaria. Boletín de Pediatría, 49, 259-292. Recuperado de: https://www.sccalp.org/documents/0000/1468/BolPediatr2009_49_259-262.pdf

Punch, R., \& Hyde, M. (2010). Children with cochlear implants in Australia: Educational settings, supports, and outcomes. Journal of Deaf Studies and Deaf Education, 15(4), 405-421. http://dx.doi.org/10.1093/deafed/enq019

Purdy, S. C., Chard, L. L., Moran, C. A., \& Hodgson, S. A. (1995). Outcomes of cochlear implants for New Zealand children and their families. Annals of Otology, Rhinology \& Laryngology, 166, 102-105.

Quittner, A. L., Barker, D. H., Snell, C., Cruz, I., McDonald, L. G., Grimley, M. E, ... Investigative Team, C. (2007). Improvements in visual attention in deaf infants and toddlers after cochlear implantation. Audiological Medicine, 5(4), 242-249, http://dx.doi.org/10.1080/16513860701745401 
Quittner, A. L., Leibach, P., \& Marciel, K. (2004). The impact of cochlear implants on young deaf children: new methods to assess cognitive and behavioral development. Archives of Otolaryngology-Head \& Neck Surgery, 130(5), 547-554. http://dx.doi.org/10.1001/archotol.130.5.547

Quittner, A. L., Smith, L. B., Osberger, M. J., Mitchell, T. V., \& Katz, D. B. (1994). The impact of audition on the development of visual attention. Psychological Science, 5(6), 347-353. http://dx.doi.org/10.1111/j.1467-9280.1994.tb00284.x

Remmel, E., \& Peters, K. (2009). Theory of mind and language in children with cochlear implants. Journal of Deaf Studies and Deaf Education, 14, 218-237. http://dx.doi.org/10.1093/deafed/enn036

Rivera, M. (2013). Análisis psicométrico del cuestionario de capacidades y dificultades (SDQ) administrado en profesores de niños y niñas escolares de la provincia de Santiago de Chile. Santiago de Chile: Universidad de Chile.

Rodríguez, M. C. (2013). El implante coclear en niños: su eficiencia funcional desde la perspectiva de las familias y los profesionales. Tenerife, España: Servicio de Publicaciones de la Universidad de La Laguna.

Rodríguez, P. J. (2006a). Trastornos psiquiátricos infantiles de etiología neurobiológica y su despistaje en Atención Primaria. Revista Pediatría de Atención Primaria, 30, 9-18.

Rodríguez, P. J. (2006b). Estudio de la prevalencia de los trastornos mentales infantiles en la Comunidad Autónoma Canaria. Tenerife, España: Servicio de Publicaciones de la Universidad de La Laguna.

Rodríguez, M. C., Pérez-Jorge, D., Alegre, O. M., Leal, E. y Suárez, M. (2016). El efecto de la implantación temprana en niños con hipoacusia. European Scientific Journal, 12(23), 25-33.

Sach, T. H., \& Whynes, D. K. (2005). Pediatric Cochlear implantation: The views of parents. International Journal of Audiology, 44, 400-407.

Schorr, E. A. (2005). Social and emotional functioning of children with cochlear implants. Maryland: University of Maryland. Recuperado de: http://drum.lib.umd.edu/bitstream/handle/1903/2408/umi-umd-2271.pdf;sequence=1

Schorr, E., Roth, F. P., \& Fox, N. A. (2009). Quality of life for children with cochlear implants: Perceived benefits and problems and the perception of single words and emotional sounds. Journal of Speech, Language, and Hearing Research, 52, 141-152. http://dx.doi.org/10.1044/1092-4388(2008/07-0213)

Silvestre, N. (2003). La comunicación en la escuela inclusiva: la atención al alumnado sordo. La Respuesta a las Necesidades Educativas Especiales en una Escuela Vasca Inclusiva. Actas del Congreso Guztientzako Eskola, Donostia-San Sebastián. País Vasco, España: Servicio Central de Publicaciones del Gobierno Vasco.

Smith, L. B., Quittner, A. L., Osberger, M. J., \& Miyamoto, R. (1998). Audition and visual attention: the developmental trajectory in deaf and hearing populations. Developmental psychology, 34(5), 840. http://dx.doi.org/10.1037/0012-1649.34.5.840

Spencer, P. E. (2004). Individual differences in language performance after cochlear implantation at one to three years of age: Child, family and linguistics factors. Journal of Deaf Studies and Deaf Education, 9(4), $395-412$. https://dx.doi.org/10.1093/deafed/enh033

Spencer, P. E., \& Marschark, M. (2003). Cochlear implants: Issues and implications. In M. Marschark (ed.), Oxford Handbook of deaf studies, language, and education, (pp. 434-442). New York: Oxford University Press.

Stevenson, J., Kreppner, J., Pimperton, H., Worsfold, S., \& Kennedy, C. (2015). Emotional and behavioural difficulties in children and adolescents with hearing impairment: A systematic review and meta-analysis. European child \& adolescent psychiatry, 24(5), 477-496. http://dx.doi.org/10.1007/s00787-015-0697-1

Stinson, M. S., \& Whitmire, K. A. (2000). Adolescents who are Deaf or hard-of-hearing: A communication perspective on educational placement. Topics in Language Disorders, 20, 58-72. http://dx.doi.org/10.1097/00011363-200020020-00006

Svirsky, M. A., Robbins, A. M., Kirk, K. L., Pisoni, D. B., \& Miyamoto, R. T. (2000). Language development in profoundly deaf children with cochlear implants. Psychological Science, 11, 153-158.

Theunissen, S. C., Rieffe, C., Kouwenberg, M., De Raeve, L., Soede, W., Briaire, J. J., \& Frijns, J. H. (2012). Anxiety in children with hearing aids or cochlear implants compared to normally hearing controls. The Laryngoscope, 122(3), 654-659. http://dx.doi.org/10.1002/lary.22502 
Viera, A. J., \& Garret J. M. (2005). Understanding interobserver agreement: The Kappa Statistic, Family Medicine, 37(5), 360-363.

Vostanis, P., Hayes, M., Feu, M., \& Warren, J. (1997). Detection of behavioural and emotional problems in deaf children and adolescents: comparison of two rating scales. Child: care, health and development, 23(3), 233-246. http://dx.doi.org/10.1111/j.1365-2214.1997.tb00966.x

Yucel, E., \& Derim, D. (2008). The effect of implantation age on visual attention skills. International journal of pediatric otorhinolaryngology, 72(6), 869-877. http://dx.doi.org/10.1016/j.ijporl.2008.02.017

\section{Copyrights}

Copyright for this article is retained by the author(s), with first publication rights granted to the journal.

This is an open-access article distributed under the terms and conditions of the Creative Commons Attribution license (http://creativecommons.org/licenses/by/4.0/). 